
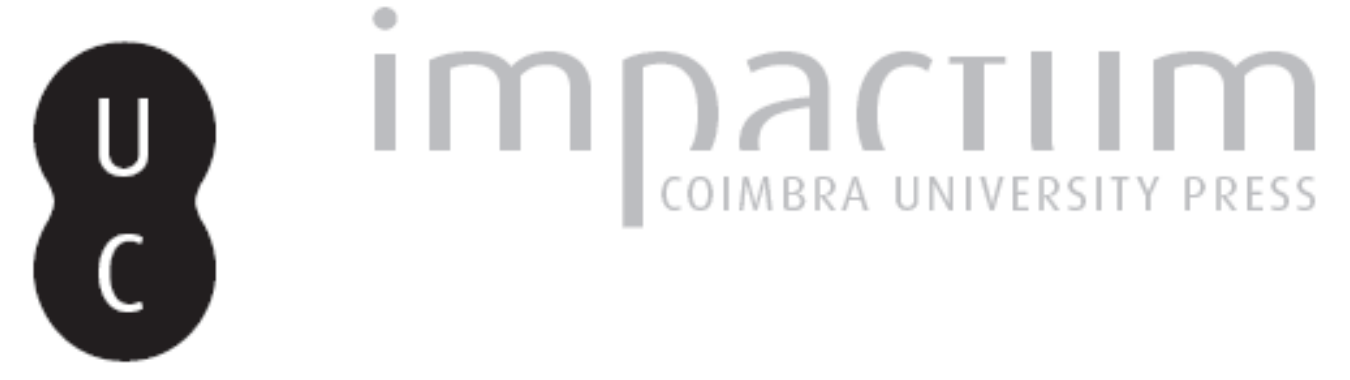

Professor Doutor Cónego Avelino de Jesus da Costa (1908-2000)

Autor(es): $\quad$ Veloso, Maria Teresa Nobre; Marques, Maria Alegria Fernandes

Publicado por: Centro de História da Sociedade e da Cultura

URL persistente:

URI:http://hdl.handle.net/10316.2/39711

DOI:

DOI:http://dx.doi.org/10.14195/1645-2259_6_9

Accessed : $\quad$ 26-Apr-2023 12:04:39

A navegação consulta e descarregamento dos títulos inseridos nas Bibliotecas Digitais UC Digitalis, UC Pombalina e UC Impactum, pressupõem a aceitação plena e sem reservas dos Termos e Condições de Uso destas Bibliotecas Digitais, disponíveis em https://digitalis.uc.pt/pt-pt/termos.

Conforme exposto nos referidos Termos e Condições de Uso, o descarregamento de títulos de acesso restrito requer uma licença válida de autorização devendo o utilizador aceder ao(s) documento(s) a partir de um endereço de IP da instituição detentora da supramencionada licença.

Ao utilizador é apenas permitido o descarregamento para uso pessoal, pelo que o emprego do(s) título(s) descarregado(s) para outro fim, designadamente comercial, carece de autorização do respetivo autor ou editor da obra.

Na medida em que todas as obras da UC Digitalis se encontram protegidas pelo Código do Direito de Autor e Direitos Conexos e demais legislação aplicável, toda a cópia, parcial ou total, deste documento, nos casos em que é legalmente admitida, deverá conter ou fazer-se acompanhar por este aviso.

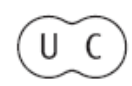




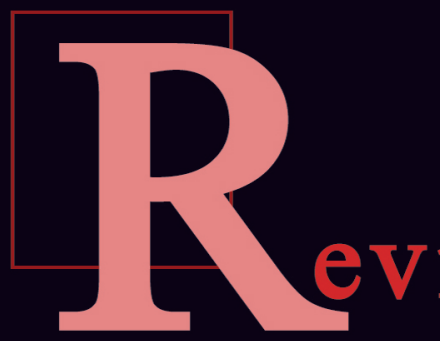

\section{da Sociedade e da Cultura}

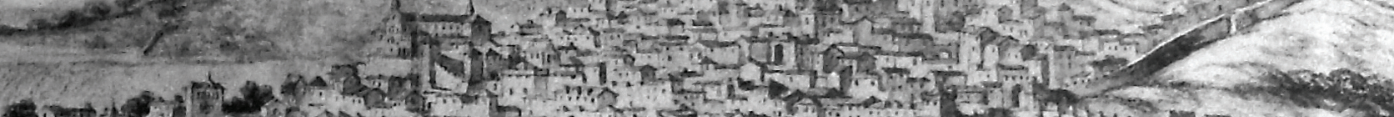

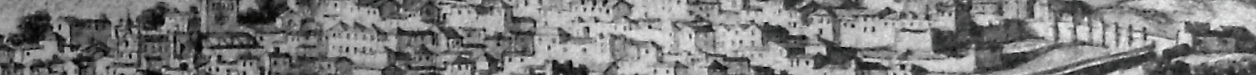

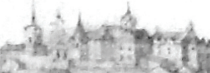

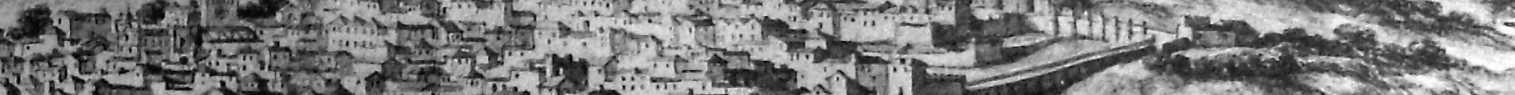

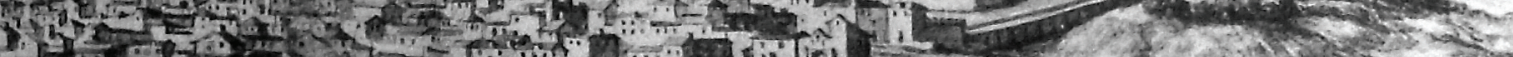

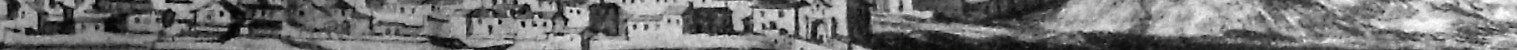

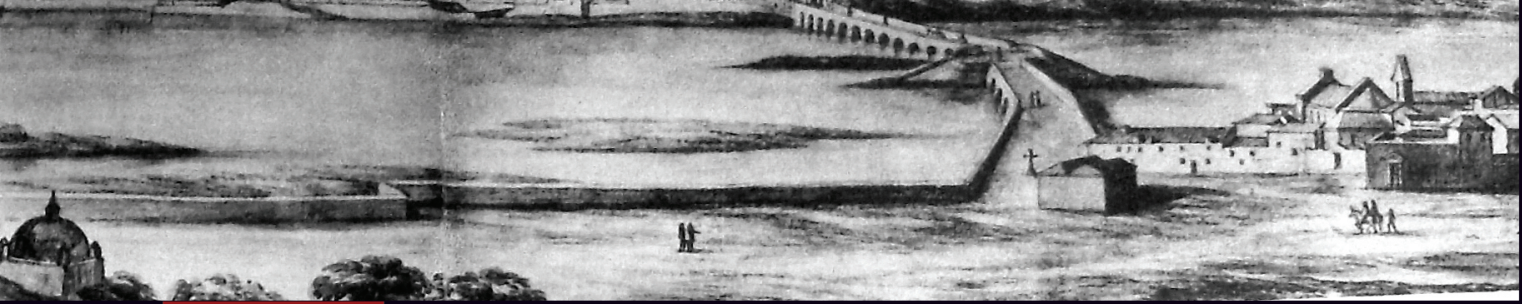

Centro de História da Sociedade e da Cultura Universidade de Coimbra

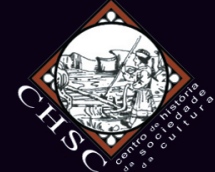




\title{
Professor Doutor Cónego Avelino de Jesus da Costa
}

(1908-2000)

\author{
Evocando a memória do Mestre
}

No próximo dia 4 de Janeiro de 2008, assinala-se o centésimo aniversário do nascimento do Professor Doutor Cónego Avelino de Jesus da Costa.

Atendendo a que o insigne Mestre foi um dos mais diligentes e carismáticos dinamizadores e obreiros do Centro de História da Sociedade e da Cultura da Universidade de Coimbra, o presente volume, que cremos venha a público por essa ocasião, não pode deixar de registar a referida efeméride.

Doutorado em 1960, o Professor Avelino de Jesus da Costa chegou ao Centro de Estudos Históricos da Faculdade de Letras da Universidade de Coimbra quando essa instituição revelava algumas dificuldades de funcionamento. O novel doutor vinha munido de excelentes credenciais visto que, de 1944 a 1952, fora já bolseiro do Instituto de Alta Cultura. Durante esses anos desenvolveu um valioso trabalho, verdadeiramente pioneiro, com a investigação que levou a cabo "em diversas bibliotecas e arquivos em busca de pergaminhos pertencentes a antigos códices litúrgicos, que, nos séculos XVI e XVII, foram desfeitos para as suas folhas servirem de capas ou de guardas de documentos e livros", segundo o testemunho que ele próprio nos deixou. O resultado desse seu paciente labor patenteia-se num extenso inventário (dactilografado), por si mesmo organizado em nove volumes.

A reestruturação do Instituto de Alta Cultura e consequente aparecimento da Junta Nacional de Investigação Científica animaram, de forma visível, o panorama científico português, no início da década de 70. Foi nessa conjuntura que o Doutor Avelino de Jesus da Costa, entretanto promovido, por concurso, a Professor Catedrático (1971), apresentou um Projecto de Investigação que pretendia dinamizar a inventariação, estudo e publicação dos diplomas pontifícios do século XIII relativos a Portugal. Recorde-se que esta temática lhe era cara e nela estava já a trabalhar, desde 1959, tendo surgido os primeiros resultados, em 1962, num relatório de 348p. apresentado à Fundação Calouste Gulbenkian, sua patrocinadora. 
Em 1973, a Junta Nacional de Investigação Científica aprovou a inclusão do Bulário Português do século XIII (1198-1303) no "Plano de Investigação CL/5" denominado "Estudo e publicação de Fontes de História de Portugal", integrado no Instituto de Estudos Históricos Doutor António de Vasconcelos, da Faculdade de Letras da Universidade de Coimbra. Três anos mais tarde, em 1976, o referido plano de investigação passou para o Centro de História da Sociedade e da Cultura daquela Universidade, integrando a então "Linha 3: HCI/3".

O Professor Avelino de Jesus da Costa constituiu a equipa de investigadores que chefiou e orientou até à data da sua morte, ocorrida em Braga, em 17 de Outubro de 2000. Os resultados da profícua actividade científica a que se entregou começaram a surgir: em 1988, doutorou-se uma das suas colaboradoras com a dissertação intitulada D. Afonso II. Relações de Portugal com a Santa Sé durante o seu reinado (dada à estampa em 2000), que tem como base documental os diplomas pontifícios relativos ao período do reinado em apreço. Em 1989, juntamente com outra das suas colaboradoras no projecto, e com o apoio do Centro de História da Sociedade e da Cultura da Universidade de Coimbra, publicava o volume I do Bulário Português, dedicado à documentação de Inocêncio III, obra de 498 páginas, com 228 documentos do citado pontífice relativos a Portugal. No ano seguinte (1990), doutorava-se outra das suas colaboradoras (essa mesma que interviera na publicação da citada obra), com a dissertação $O$ Papado e Portugal no tempo de D. Afonso III (1245-1279), igualmente elaborada tendo como base o núcleo documental da documentação pontifícia relativa ao período em questão.

"Reconhecendo que o Bulário Português - escreve o saudoso Mestre, na introdução do Bulário Português. I. Inocêncio III...-, é indispensável para os historiadores da nossa Idade Média, por constituir uma série documental de valor histórico comparável ao das Chancelarias régias portuguesas, tentámos - continua o referido Professor - durante anos, iniciar a sua publicação até conseguirmos, finalmente, que o Instituto Nacional de Investigação Científica o incluísse no seu Planeamento Editorial da série "Textos de História".

Com o imprescindível apoio do Centro, o plano traçado (e sempre superiormente orientado pelo insigne Mestre) foi prosseguindo, achando-se, no presente, bastante adiantada a preparação dos diplomas subsequentes, aos 
quais foi acrescentada vasta documentação inicialmente omissa no relatório apresentado pelo Professor Doutor Avelino de Jesus da Costa.

Ao saudoso Mestre, que tão genuína e generosamente soube associar as suas altas qualidades humanas à actividade docente e de Investigador, o nosso testemunho de eterna gratidão,

Maria Teresa Nobre Veloso,

Maria Alegria Fernandes Marques,

Coimbra, 17.Outubro.2007 